\title{
DIGENEAN TREMATODES OF MARINE TELEOST FISHES : THE GENUS HELICOMETRA ODHNER, 1902 (OPECOELIDAE) :ON THE VALIDITY OF TWO KNOWN SPECIES FROM THE RED SEA
}

\author{
Reda M. El-Said Hassanine \\ Depratment of Biology, New Valley Faculty of Education, Assiut \\ University, El-Kharga, New Valley, Egypt
}

Key words: Trematoda, Digenea, Opecoelidae, Helicometra, Red Sea fishes.

\section{ABSTRACT}

The genus Helicometra Odhner, 1902 (Trematoda : Digenea : Opecoelidae) was briefly reviewed. The digeneans now referred to H. marmoratae Nagaty and Abdel-Aal, 1962 and H. nasae Nagaty and Abdel-Aal, 1962 were collected from their original fish hosts at Hurgada, Red sea, Egypt. These species are redescribed in details and figured. The given redescriptions are broadened and revealed that $H$. marmoratae is actually a synonym of $H$.pulchella (Rudolphi, 1819) Odhner, 1902 (the type species of the genus), while $H$. nasae is actually a synonym of $H$. equilata (Manter. 1933) Siddiqi and Cable, 1960. However, the misidentification of these species was discussed.

\section{INTRODUCTION}

Helicometra Odhner, 1902 (Trematoda: Digenea: Opecoelidae) is a large cosmopolitan genus. Through the years 1902-1973, many of its species underwent numerous taxonomic changes and a large number of synonyms were proposed. Therefore, Sekerak and Arai (1974) comprehensively reviewed this genus accepting the validity of 15 out of 31 species known at that time. These are: H. pulchella (Rudolphi, 1819) odhner, 1902 (the type species) [synonyms $=H$. simuata (Rudolphi, 1819) Odhner, 1902, H. fasciata (Rudolphi, 1819) Odhner, 1902, H. mutabilis stossich, 1903, H. flava (Stossich, 1902) Stossich, 1903, H. gobii (Stossich, 1883) Stossich, 1904, H. labri (Stossich, 1886) Isaichikov, 1928. H. epinepheli Yamaguti, 1934, H. hypodytis Yamaguti, 1934, H. markewitschi Pogorel'tseva, 1954, H. dochmosorchis Manter and Pritchard, 1960, H. aposinuta Pritchard, 
1966, and H. upapalu Yamaguti, 1970], H. torta Linton, 1910 (synonym $=H$. pretiosa Bravo-Hollis and Manter, 1957), $H$. plovmornini Isaichikov, 1928, H. tenuifola Woolcock, 1935 (synonym $=H$. neosebastodis Crowcroft, 1947), H. bassensis Woolcock, 1935, H. grandora Manter, 1954, H. pteroisi (Gupta, 1956) Siddiqi and Cable, 1960, H. equilata (Manter, 1933) Siddiqi and Cable, 1960 (synonym $=H$. boseli Nagaty, 1956), H. marmoratae Nagaty and Abdel-Aal, 1962, H. nasae Nagaty and Abdel-Aal, 1962 (synonym $=H$. rectisaccus Fischthal and Kuntz, 1964), H. indica Agrawal, 1964, H. borneoensis Fischthal and Kuntz, 1965, H. kyliotrema Pritchard, 1966, H. paracirrhiti Pritchard, 1966 and $H$. gomphosi Yamaguti, 1970. Through the years 1974-1993, 5 additional species have been ascribed to the genus Helicometra; namely $H$. robinsorum Overstreet and Martin, 1974, H. filamentosa Madhavi, 1975, H. sinipercae Wang, 1982, H. scorpaenae Wang, 1982, and H. gibsoni Meenakshi and Swarnakumari, 1993. Thus, the genus is now comprising 20 valid species.

Until now, 4 species of Helicometra are known from the Red Sea fishes; namely H. pulchella (Rudolphi, 1819) Odhner, 1902 [described as H. hypodytis Yamaguti, 1934 by Nagaty (1956), and as H. epinepheli Yamaguti, 1934 by Ramadan (1986)], H. equilata (Manter, 1933) Siddiqi and Cable, 1960 [described as H. boseli by Nagaty (1956)], H. marmoratae Nagaty and Abdel-Aal, 1962, and $H$. nasae Nagaty and Abdel-Aal, 1962. To date, H. marmoratae and $H$. nasae are only known by their original descriptions since 1962. The validity of these species was questioned by Sekerak and Arai (1974) who stated that "further collections of these species are required to establish their validity". In fact, the original descriptions of $H$. marmoratae and H. nasae were inadequate, for example, the first species was briefly described from one specimen only. In the present study, the digeneans now referred to H. marmoratae and $H$. nasae were collected from their original fish hosts at Hurgada, Red Sea, Egypt (Fig. 1) and redescribed in details to discuss their validity.

\section{MATERIAL AND METHODS}

In January 2001, 42 and 26 individuals of the fish Teuthis marmorata (local name= Sigan) and Epinephelus fasciatus (local name $=$ Koshar) respectively, were collected from the coasts of 
Digenean trematodes of marine teleost fishes:The genus 85

Helicometra Odhner, 1902 (Opecoelidae) :on the validity of two known species from the Red Sea

Hurgada, Red Sea, Egypt. Standard parasitological techniques were used to examine the alimentary canal of fish. Digenean trematodes were removed from their host fishes under a dissecting microscope, kept alive in sea water diluted to $1 \%$ salinity as recommended by Schroeder (1971), and observed under a compound research microscope. Some worms were fixed in alcohol-formalin-acetic (AFA) under slight coverslip pressure, and preserved in $70 \%$ ethyl alcohol. Whole mounts were stained by alum carmine, cleared in terpineol, and mounted in Canada balsam. Figures were drawn with the aid of a camera lucida. Mounted specimens were deposited in the Helminthological collection of the Red Sea fishes, Marine Science Department, Faculty of Science, Suez Canal University, Ismailia, Egypt.

\section{RESULTS AND DISCUSSION}

\section{Helicometra marmoratae Nagaty and Abdel-Aal, 1962 (Fig. 2 A)}

Out of 42 Teuthis marmorata examined, 6 individuals $(14.29 \%)$ were found parasitized by the intestinal trematode Helicometra marmoratae Nagaty and Abdel-Aal, 1962. The following description of this species is based on 30 mounted specimens:

The body is elongate, somewhat flattened dorso-ventrally. unspined, and measures $3.20-6.10 \mathrm{~mm}$ long by $0.75-1.33 \mathrm{~mm}$ wide at the acetabular level. The oral sucker is sub-terminal, nearly spherical, and measures $0.26-0.45 \mathrm{~mm}$ in diameter. The acetabulum is spherical, $0.38-0.70 \mathrm{~mm}$ in diameter, and situated at the middle of the anterior half of body. Sucker ratio is about 1:1.46-1.63. Forebody is about one fourth of the total body length. The pharynx is globular, and measures $0.17-0.28 \mathrm{~mm}$ long by $0.19-0.33 \mathrm{~mm}$ wide. The oesophagus is short, $0.10-0.18 \mathrm{~mm}$ in length, and bifurcates at about the mid-way between suckers into two narrow intestinal caeca extending backwards to near the posterior extremity. The two testes are slightly lobed, slightly separated, oblique (in 18 specimens) or tandem (in 12 specimens), and situated post-equatorial or at the middle of the posterior half of body. anterior testis measures $0.39-0.65 \mathrm{~mm}$ long by $0.32-0.52 \mathrm{~mm}$ wide, 
while the posterior one measures $0.42-0.65 \mathrm{~mm}$ long by $0.28-0.50 \mathrm{~mm}$ wide. The cirrus sac is well developed, overlapping the anterior border of acetabulum posteriorly, sigmoid (dextral in 20 specimens) or clavate (median in 10 specimens), and measures 0.56-0.95 $\mathrm{mm}$ long by $0.13-0.19 \mathrm{~mm}$ wide. It contains a slightly twisted seminal vesicle, a well developed prostatic complex, and a relatively long protrusible cirrus the genital pore is median, just behind the intestinat bifurcation. The ovary is multi-lobed, situating sub-median to right. and contiguous with the anterior testis. The seminal receptacle is rounded. and occupies different positions anterior to the ovary. I aurer's canal is a direct continuation of the seminal receptacle. and opening dorsally near the median line at the level between the ovary and acelabulum. The uterus is relatively long. inter-caecal, winding between the ovary and acetathulum. The terminal uterine coil is muscular. and forms a distince metraterm opening into the base of the genital atrium. The vitelline follicles are irregular in shape, small in size, numerous, and extend in the lateral fields from the level of pharynx to near the posterior extremity; confluent in post-testicular space. The eggs are thin-shelled, moderately large, $62-78 \mu \mathrm{m}$ long by 40-54 $\mu \mathrm{m}$ wide, and provided with polar filaments $2-3$ times the egg length. The excretory vesicle is saccular, extending anteriorly to near the acetabulum; the excretory pore is postero-terminal.

Helicometra marmoratae Nagaty and Abdel-Aal, 1962 was briefly described from one specimen and only compared with $H$. hypodytis Yamaguti, 1934 (now is a synonym of $H$. pulchella). Nagaty and Abdel-Aal (1962) mentioned that H. marmoratae is very similar to H. hypodytis, but differs in having oblique testes (instead of being tandem), a spherical seminal receptacle (instead of being oval), and a median genital pore situating immediately behind the intestinal bifurcation (instead of situating at the level of oesophagus). At that time, this comparison was inappropariate, since $H$. pulchella and $H$. dochmosorchis Manter and Pritchard, 1960 (now is a synonym of $H$. pulchella) shared these characteristics with $H$ marmoratae. Undoubtedly, many variations occur during relaxation, fixation, and further preparation of the specimens for study. For example, the tandem testes tend to be oblique during relaxation; the shape of seminal receptacle varies greatly depending upon its content (i.e, reflects its content); the position of genital pore may appear to be greatly affected by the state of contraction of the specimen Accordingly, all the characteristics used by Nagaty and Abdel-Aa! 
(1962) were invalid specific differences in distinguishing $H$. marmoratae from $H$. hypodytis. However, Sekerak and Arai (1974) gave convincing evidences that the sucker ratio, the forebody length (the region between the anterior end of body and the anterior border of acetabulum, i.e, the position of acetabulum), the anterior extent of vitelline follicles, the posterior extent of the cirrus sac, and the egg size are the most important five taxonomic characters in separating species of the genus Helicometra from each others. In fact, $H$. marmoratae was poorly described from one specimen only by Nagaty and Abdel-Aal (1962). However, the given description includes some errors, for example, it stated that the posterior part of the cirrus sac was immediately pre-testicular, but the illustration (Fig. 3 of Nagaty and Abdel-Aal 1962) clearly shows the posterior part of the cirrus sac to overlap the anterior border of acetabulum. It should, therefore, be assumed that "pre-testicular" is an error and should be replaced by "pre-acetabular". In the present study, the description of H.marmoratae was broadened and critically compared with that of $H$. pulchella in Table (1). As shown in this table, H. marmoratae has no specific difference which would distinguish it from $H$. pulchella to establish its validity. However, all the characteristics of $H$. mormoratae are now overlapping those of $H$. pulchella. In view of the above information, it is concluded that H. marmorate Nagaty and Abdel-Aal, 1962 is actually a synonym of $H$. pulchella (Rudolphi, 1819) Odhner, 1902 (the type species of the genus).

\section{Helicomentra nasae Nagaty and Abdel-Aal, 1962 (Fig. 2B)}

Out of 26 Epinephelus fasciatus examined, 7 individuals $(26.92 \%)$ were found parasitized by the intestinal trematode Helicometra nasae Nagaty and Abdel-Aal, 1962. The following description of this species is based on 45 mounted specimens:

The body is elongate, dorso-ventrally flattened (lateral margins are nearly parallel), unspined, and measures $2.90-5.83 \mathrm{~mm}$ long by $0.38-0.65 \mathrm{~mm}$ wide at its middle. The oral sucker is sub-terminal. spherical and measures $0.16-0.26 \mathrm{~mm}$ in daimeter. The acetabulum is spherical, $0.19-0.32 \mathrm{~mm}$ in diameter, and situated posteriorly in the anterior fourth of the body. Suker ratio is about $1: 1.18-1.23$. Forebody is about one fifth of the total body length. The pharynx is globular, and measures $0.08-0.14 \mathrm{~mm}$ long by $0.11-0.16 \mathrm{~mm}$ wide. 
The oesophagus is moderately long, $0.12-0.18 \mathrm{~mm}$ in length, and bifurcates at about the mid-way between suckers into two narrow intestinal caeca extending backwards to near the posterior extremity. The two testes are tetra-lobed, tandem, slightly separated, and situated anteriorly in the posterior half of the body; anterior testis measures $0.29-0.52 \mathrm{~mm}$ long by $0.24-0.46 \mathrm{~mm}$ wide, while the posterior one measures $0.33-0.61 \mathrm{~mm}$ long by $0.23-0.50 \mathrm{~mm}$ wide. The vasa deferentia arise from the testes are united anterior to the ovary to form a common vas deferens opening into the base of the cirrus sac. The later organ is sinistral, $0.60-1.22 \mathrm{~mm}$ in length, and contains a slightly widing seminal vesicle, a well developed prostatic complex and a relatively long protrusible cirrus. The genital pore is nearly median, ventral to the oesophagus. In some specimens (especially the small ones), the cirrus sac seemed to be sigmoid and extending posteriorly to the mid-way between the acetabulum and ovary, but in the other specimens (large ones), the cirrus sac seemed to be slightly curved and extending posteriorly to about one third of the distance between the acetabulum and ovary. The ovary is tetra-lobed, median, situated at a short distance anterior to the testes, and measures 0.19-0.33 mm long by $0.21-0.37 \mathrm{~mm}$ wide. The seminal receptocle is oval in shape, and lies immediately in front of the ovary. Laurer's canal originates directly from the seminal receptacle, and opens medially on the dorsal side of the body. The uterus is relatively long, inter-caecal, and coiled between the ovary and acetabulum. The terminal uterine coil is nearly straight and extending along the median line to open into the genital atrium. The vitelline follicles are numerous, irregular in shape, and extending anteriorly to near the posterior border of acetabulum; confluent in post-testicular space. At the ovarian level, a transverse vitelline duct coming from the vitellaria of each side to open into a saccular vitelline reservior situating ventral to the ovary. The eggs are thin-shelled, 45-55 $\mu \mathrm{m}$ long by 28-35 $\mu \mathrm{m}$ wide, and provided with polar filaments slightly longer than the egg length. The excretory vesicle is tubular, extending anteriorly to near the ovary; the excretory pore is postero-terminal.

Helicometra nasae Nagaty and Abdel-Aal, 1962 was briefly described from 10 specimens and only compared with $H$. boseli Nagaty, 1956 (now is a synonym of $H$. equilata). Nagaty and Abdel. Aal (1962) mentioned that $H$. nasae is similar to $H$. boseli, but the former differs in having a cirrus sac extending well posterior to the acetabulum, vitelline follicles extending anteriorly to the posterior edge of acetabulum, and an ovary situating some distance in front of 
the anterior testis. Except the posterior extension of the cirrus sac, the other two characteristics used by Nagaty and Abdel-Aal (1962) were no longer useful in distinguishing $H$. nasae from $H$. boseli. However, at that time this comparison is inappropriate, since $H$. equilata (Manter, 1933) Siddiqi and Cable, 1960 shared these characteristics with $H$. nasae, but Nagaty and Abdel-Aal (1962) seemed unaware of the study of Siddiqi and Cable (1960). In fact, $H$. nasae was poorly described by Nagaty and Abdel-Aal (1962). Also, the given description includes some errors, for example, it stated that "the acetabulum is located nearly in the anterior third of the body length", but the illustration (Fig. 2 of Nagaty and Abdel-Aal 1962) clearly shows the acetabulum to locate in the anterior fifth of the body. Skerak and Arai (1974) preferred to keep H. nasae Nagaty and Abdel-Al, 1962 as a valid species and stated that the only difference between $H$. nasae and $H$. equilata is the characteristic of the cirrus sac. In the former, the cirrus sac is slightly curved and extends posteriorly to about one third of the distance between the acetabulum and ovary, but in the second, the cirrus sac is sigmoid and extending to the mid-way between the acetabulum and ovary. This characteristic seems questionable, since Pritchard (1966) reported sigmoid to slightly curved cirrus sacs in her specimens of $H$. boseli (now is a synonym of $H$. equilata). However, it has been demonstrated in $H$. pulchella and $H$. equilata that considerable intraspecific variations occur in the shape of the cirrus sac and its orientation with respect to the acetabulum (Sekerak and Arai, 1974). In the present study, the description of $H$. nasae was broadened to reveal that in small specimens the cirrus sac is usually sigmoid, and extends posteriorly to the mid-way between the acetabulum and ovary; but in large specimens, the cirrus sac is slightly curved and extends posteriorly to about one third of the distance between the acetabulum and ovary. Thus, the shape and posterior extent of the cirrus sac are herein considered as invalid specific characteristics if the description is not broadened. The present description of $H$. nasae was compared critically with that of H. equilata in Table (2). As shown in this table, $H$. nasae has no specific difference which would distinguish it from H. equilata to establish its validity. However, all the characteristics of $H$. nasae are now overlapping those of $H$. equilata. Accordingly, it is concluded that $H$. nasae Nagaty and Abdel Aal, 1962 is actually a synonym of $H$. equilata (Manter. 1933) Siddiqi and Cable, 1960. 


\section{REFERENCES}

Agrawal, V. (1964). On a trematode Helicometra indica n. sp. from the intestine of the gurnard fish, Trigla gurnardus. Proc. Helminthol. Soc. Wash., 31: 216-218.

Bravo-Hollis, M. and MANTER, H.W. (1957). Trematodes of marine fishes of Mexican waters. X. Thirteen Digenea, including nine new species and two new genera from the Pacific coast. Proc. Helminthol. Soc. Wash., 24 :35-48.

Crowcroft, P. W. (1947). The anatomy of two new digenetic trematodes from Tasmanian food fishes. Proc. Linn. Soc. N.S.W., $71: 108-118$.

Fischthal, J. H., and KUNTZ, R. E. (1964). Digenetic trematodes of fishes from Palawan Island, Philippines. Part II. Five Opecoelidae, including three new species. Proc. Helminthol. Soc. Wash., 31: 40-46.

Fischthal, J. H., and KUNTZ, R. E. (1965). Digenetic trematodes of fishes from North Borneo (Malaysia). Proc. Helminthol. Soc. Wash., $32: 63-71$.

Gupta, N. K. (1956). Studies on the digenetic trematodes of marine fishes from the Gulf of Manaar (India). Res. Bull. Panjab Univ. Sci., 89: 61-63.

Isaichikov, I. M. (1928). Information on some parasitic worms of vertebrates of the Russian Arctic. Trudy Morsk. Nauchn. Inst., 3 :5-79.

Linton, E. (1910). Helminth fauna of the Dry Tortugas. II. Trematodes. Carnegie Inst. Wash. Publ.; Pap. Tortugas Lab., 4:11-98.

Madhavi, R. (1975). Digenetic trematodes from marine fishes of Waltair Coast, Bay of Bengal, Family Opecoelidae. Riv. Parassitol., $36: 153-164$. 
Digenean trematodes of marine teleost fishes :The genus $\quad 91$ Helicometra Odhner, 1902 (Opecoelidae) :on the validity of two known species from the Red Sea

Manter, H. W. (1933). The genus Helicometra and related termatodes from Tortugas, Florida. Carnegie Inst. Wash. Publ., Pap. Tortugas Lab., $28: 169-180$.

Manter. H. W. (1954). Some digenetic trematodes from fishes of New 7.ealand. Trans. Roy. Soc. New Zealand, $82: 475-568$.

Manter. H. W. and Pritchard, M. H. (1960). Some digentic termatodes of eels of Hawaii. J. Parasitol. 46:651-658.

Mcenakshi, M. and Swarnakumari. V. G. (1993). The life cycle of Helicomelra gih.smi n. sp. (Digenea: Opcoselidae). Syst Parasitol. 25:6i-72.

Nagaty, H. F. (1956). Trematodes of fishes from the Red Sea. Part 7. On two gyliauchenids and three allocreadiids, including four new species. I. Parasitol. +2 : 523-527.

Nagaty, H F.. and Abdel-aal, T. M. (1962). Trematodes of fishes from the Red Sea. Part 17. On three allocreadiid sp.and one schistorchiid sp. J. Arab. Vet. Med. Assoc., 22: 307-314.

Odhner. T. (1902). Mitteilung zur kenntnis der Distomen. Zentrlhl. Bakterial. Parasitenkd. Infek. Hyg. Abt. 1 orig., 31 : 58-69.

Overstreet. R. M. and Martin. D. M. (1974). Some digenetic trematodes from Sylnaphobranchid eels. J. Parasitol., 60: $80-84$

Pogorei'Tseva, T. P. (1954). New species of digenetic worms from fishes of the Black Sea. Nauk Zap. Kam'iantsiapodil' skoho Derzh. Pedagogo. Inst. Biol. Ser., 2: 133-137.

Pritchard, M. H. (1966). Studies on digenetic trematodes of Hawaiian fishes: Family Opecoclidae Ozaki. 1925. Zool. Jb. Abt. Syst. $03: 173-202$.

Ramadan, M. M. (1986). Trematodes of the genera Helicometra Odhner. 1902 (Opecnelidae) and Aspharyngogliauchen 
Yamaguti, 1942 (Gyliauchenidae) from the Red Sea fishes. Jap. J. Parasitol., 35:483-490.

Rudolphi, C. A. (1819). Entozoorum synopsis cui accedunt mantissa duplex et indices locupletissimi. Berolini, $1: 1-811$.

Schroeder, R. E. (1971). Ecology of intestinal trematodes of the gray snapper, Lutjanus grisueus, near lower Matecumbe key, Florida, with a description of a new species. Stud. Trop. Oceanogr. Miami, 10:151-221.

Sekerak, A. D. and Arai, H. P. (1974). A revision of Helicometra Odhner, 1902 and related genera (Trematoda : Opecoelidae), including a description of Neohelicometra sebastis n. sp. Canad. J. Zool., 52 : 707-738.

Siddiqi, A. H. and Cable, R. M. (1960).Digenetic trematodes of marine fishes of Puerto Rico. Scient. Surv. Puerto Rico and Virgin Isl., $17: 257-369$.

Stossich, M. (1903). Una nuova specie di Helicometra Odhner. Arch. Parasitol., $7: 373-376$.

Stossich, M. (1904). Alcuni distomi delle collezione elminatologia del museo zool. d. Napoli. Ann. Mus. Zool. R. Univ., l : 1-14.

Wang, P. Q. (1982). Some digenetic trematodes of marine fishes from Fujian Province, China. Oceanol. et Limnol. Sin, 13 : 179194.

Woolcock, V. (1935). Digenetic trematodes from some Australian fishes. Parasitol., 27 : 309-331.

Yamaguti, S. (1934). Studies on the helminth fauna of Japan. Part 2. Trematodes of fishes. I. Jap. J. Zool., $5: 249-541$.

Yamaguti, S. (1970). Digenetic trematodes of Hawaiian fishes. Tokyo: Keigaku Publishing CO., 436 pp. 

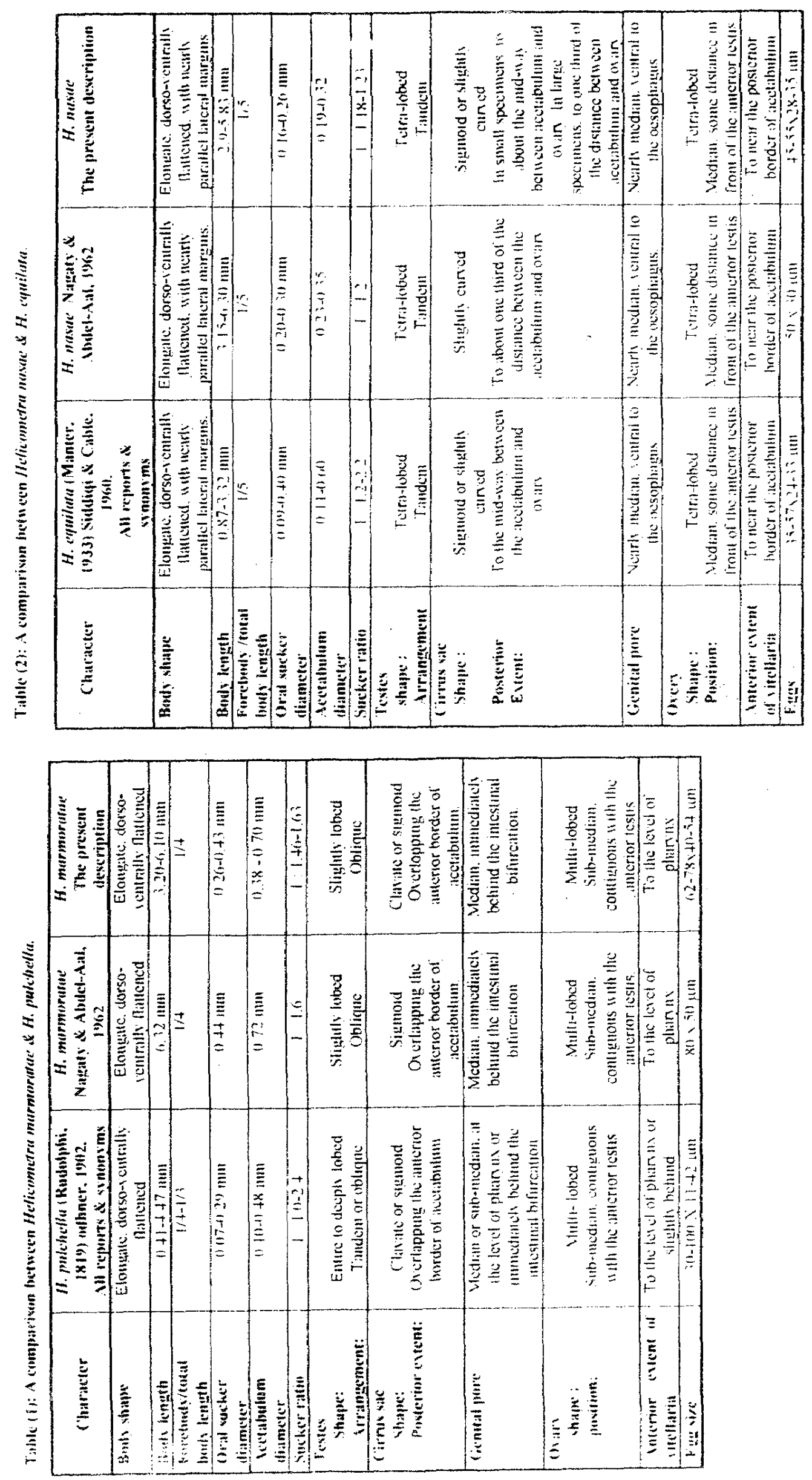


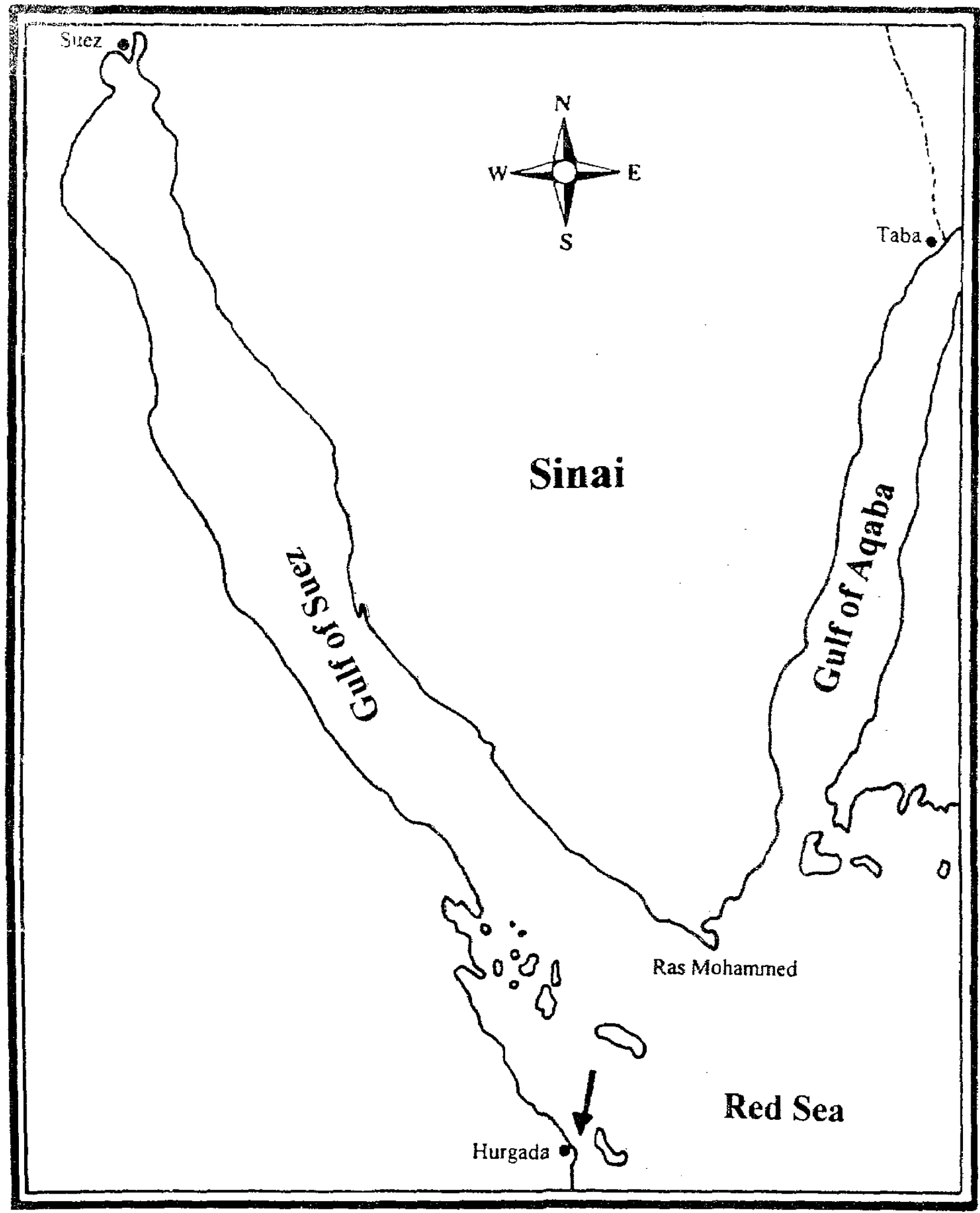

Fig. (1): A map showing the locality of the examined fishes . 

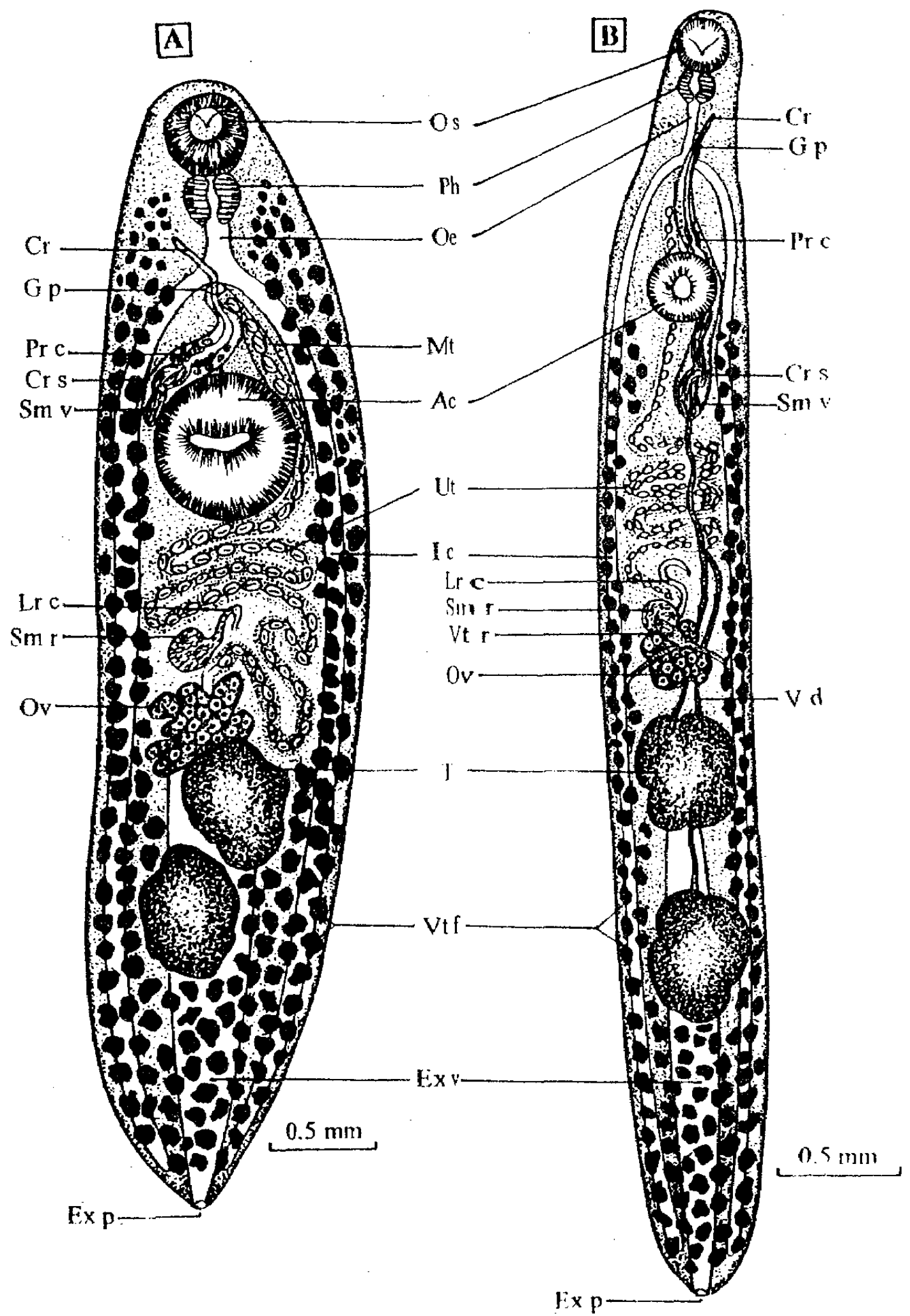

Fig.(2): A) Helicometra marmoratae Nagaty and Abdel-Aal, 1962 (ventral view). B) Helicometra nasae Nagaty and Abdel-Aal, 1962 (ventral view). $A_{c}=$ Acetabulum, $C r=$ Cirrus, $C r s=$ Cirrus sac, Ex $p=$ Excretory pore, Ex v= Excretory vesicle, $\mathrm{G}$ p= Genital pore, I $\mathrm{c}=$ =Intestinal caccum, $\mathrm{L}, \mathrm{c}$-laurer's canal, Mt=Metraterm, Oe=Oesophagus, O $\mathrm{s}=$ Oral sucker, Ov-Ovary, $\mathrm{Ph}=$ Pharynx, $\mathrm{Pr} \mathrm{c}=$ Prostatic complex, Sin $\mathrm{r}=$ Seminal receptacle, Sin $v=$ Seminal vesicle, $T-$ Testis, Ut $-I$ lerus, $v d=V$ as deferens, $V t f-V$ itclline follicles, $\mathrm{Vt} r=$ Vitelline reservoir. 